\title{
La formación de capacidades en las comunidades eclesiales de base en una colonia de la zona metropolitana de Guadalajara
}

\section{Formation of capabilities on the ecclesial base communities in the neighborhood of Guadalajara metropolitan area}

\author{
José Humberto Salguero Antelo*
}

Con el apoyo de la hermenéutica analógica, este artículo recupera los diferenciales pedagógicos de las prácticas que, con un enfoque pastoral, se realizaron en las comunidades eclesiales de base en una colonia de la zona metropolitana de Guadalajara en los años 1973-1995, periodo en el que surgieron diversas luchas reivindicativas tanto por el reclamo de servicios básicos del lugar como por cobros injustos derivados de la venta de los predios habitados por familias provenientes del entorno rural. De estas luchas, así como de diversas acciones de estas comunidades, se derivaron algunos diferenciales pedagógicos que tienen como significación la formación de capacidades.

This article is committed to the search for education in environments other than schooling, which is why with the support of analogic hermeneutics the pedagogical differentials of the practices that from the pastoral approach were carried out by the Base Ecclesial Communities in a neighborhood located south of the Guadalajara metropolitan area in the years of 1973-1995. During this period several protest struggles were carried out both for the claim of basic services of the place and for unfair charges derived from the sale of the properties inhabited by families from the rural environment. From these struggles, as well as from various actions of these communities, some pedagogical differentials are derived, whose significance is the formation of capabilities presented in this paper.
Palabras clave:

enfoque de capacidades, actitudes prosociales, conductas prosociales, formación comunitaria, hermenéutica

\section{Keywords:}

capabilities approach, prosocial attitudes, prosocial behaviors, community training, hermeneutics

Recibido: 17 de febrero de 2020 | Aceptado para su publicación: 13 de noviembre de 2020 | Fecha de publicación: 19 de noviembre de 2020

Recuperado de: https://sinectica.iteso.mx/index.php/SINECTICA/article/view/1113 doi: 10.31391/S2007-7033(2020)0055-014

\footnotetext{
* Doctor en Educación por la Universidad La Salle Noroeste. Profesor investigador de la Universidad La Salle Noroeste. Líneas de investigación: impacto social de la educación, epistemología de las ciencias sociales, la educación ética. Correo electrónico: jsalguero@ulsa-noroeste.edu.mx
} 


\section{INTRODUCCIÓN}

T a existencia percibida como fatalidad se vive como inevitable, inmodificable e irremediable. La vida, así experimentada, se asume como destino, programa o sentencia vivida desde una conciencia mimética a lo dado. En estas condiciones, el pensamiento crítico, el diálogo y la autoconciencia, elementos que definen la esencia humana, dejan de tener relevancia ante la realidad que prescinde del pensar, donde solo hay que obedecer y reproducir; donde no hay diálogo, porque la propia palabra se suprime y únicamente hay que escuchar a sus dueños vigentes; la autoconciencia carece de relevancia ante la imposición de las vigencias colectivas.

La deshumanización radica en aquellas disposiciones orientadas a la negación de lo que constituye la esencia humana, por lo que la humanización se construye en los caminos para revertir estas tendencias que desfavorecen el despliegue óptimo de la vida. A partir de estos caminos, la educación es la ruta idónea para pensar de manera crítica la realidad, para suscitar el diálogo desde la afirmación de la propia palabra y la del otro, y para favorecer procesos de autoconciencia. Si la educación es un conjunto de disposiciones encaminadas a la superación de la existencia como fatalidad, surge la pregunta orientadora: ¿es posible que la educación pueda contribuir a la superación de esta condición de fatalidad? De ser así, ¿cómo puede ser esto posible?, ¿con qué se cuenta para lograrlo?

\section{Contexto del estudio: colonia lomas de Polanco}

El marco temporal de los resultados de esta investigación abarca de 1973 a 1995, y se ubica en la colonia Lomas de Polanco, al sur de la zona metropolitana de Guadalajara. Este tiempo y espacio estuvieron marcados por la llegada y salida de los jesuitas a la colonia (Gómez, 2011). En esta zona se dio un proceso de migración particular entre 1940 y 1970 impulsado por la crisis del campo y la industrialización de la ciudad (Ramírez y Nuncio, 1994). Los primeros asentamientos se hicieron en terrenos que formaban parte de los ejidos de Santa María Tequepexpan y El Polanco, los cuales se comenzaron a fraccionar (Morfín, 1979).

La venta de los predios se realizó en condiciones irregulares (Morfín, 1979) y, derivado de ello, los servicios públicos y de alcantarillado eran deficientes, sumado a la falta de escrituración de los lotes (Gómez, Penilla, Vaca y Pérez, 2015). Estas carencias originaron movilizaciones sociales. Las comunidades eclesiales de base (CEB) de la colonia Lomas de Polanco fueron promovidas y animadas por la llegada de los jesuitas al lugar en el marco de la opción preferencial por los pobres fomentada por la Iglesia en esos años (Gómez et al., 2015).

\section{La opción por los pobres y las comunidades eclesiales de base}

La opción preferencial por los pobres fue promovida por la Iglesia latinoamericana a partir del Concilio Vaticano II (Floristán, 1998) y las conferencias episcopales llevadas a cabo en la región, especialmente las de Puebla, en 1979, y Santo Domingo, en 1992 (Dussel, 1979). “Consiste en la decisión voluntaria que conduce a encarnarse en el mundo de los pobres para asumir con realismo histórico su causa de liberación integral" (Lois, 1991, p. 9). Pretende conjugar la praxis ética del cristianismo con la 
búsqueda de la justicia ante la indignación de la pobreza como realidad lacerante de la dignidad de la persona. Esta indignación parte de una crítica a las condiciones estructurales generadores de la pobreza, en la cual la filantropía como respuesta se juzga como insuficiente ante la necesidad de asumir las demandas de los pobres a los que se les adjudica la categoría bíblica de pueblo (Boff, 1992); por ello, se habla de una iglesia popular para emprender un proceso de transformación de estas estructuras identificado como liberación (Dussel, 1979).

Como resultado, surge un nuevo modelo de iglesia con las bases populares (Vázquez, 1997), la cual supone relaciones entre el pueblo y las jerarquías con mayor horizontalidad y participación en la praxis pastoral tradicional (Richard, 2008). En este contexto nacen las CEB (Novaes, 1995), que no definen una iglesia para los pobres, como destinatarios u objetos, sino de los pobres, que se constituyen como sujetos, uno de los propósitos de su pastoral: "Alentar y favorecer todos los esfuerzos del pueblo por crear y desarrollar sus propias organizaciones de base, por la reivindicación y consolidación de sus derechos y por la búsqueda de una verdadera justicia" (CELAM, 1968).

La praxis educativa de las CEB se lleva a cabo con el método ver, juzgar y actuar; en él la realidad local se hace presente como tema de reflexión (ver), interpretada a la luz de las enseñanzas bíblicas (juzgar) para respaldar la acción (actuar) (Boff, 1990). Surgió en Europa y fue reformulado en las CEB con la influencia pedagógica del método reflexión-acción de Paulo Freire, que contribuyó a formar la conciencia social entre sus miembros (Richard, 1984).

Este método formaba parte de las reuniones semanales que tenían en pequeños grupos las comunidades. A su vez, las actividades que realizaban (formación religiosa, celebraciones litúrgicas, acciones de evangelización, retiros, iniciativas de filantropía y sociales, como cooperativas, y participación en movimientos sociales) tenían un tinte educativo de concientización (Vázquez, 1997). Algunas comunidades, con base en esta dinámica, llegaron a una madurez de compromiso cristiano en lo político que concretó su práctica en la formación de asociaciones de vecinos para la búsqueda de diversas reivindicaciones locales.

\section{Las comunidades eclesiales de base en la colonia Lomas de Polanco}

Las CEB inician en 1971 en la colonia cercana de Santa Cecilia, con actividades de evangelización, educación popular, concientización y organización emprendida por los agentes de pastoral, entre los que estaban fundamentalmente sacerdotes jesuitas, con la participación de sacerdotes diocesanos y religiosas simpatizantes con la praxis organizativa de las CEB (Ramírez y Nuncio, 1994). En 1973 existían 80 grupos creados con este proceso, la mayoría de ellos de evangelización, salud, vivienda, cooperativas, salud y música (Ramírez y Nuncio, 1994).

En ese mismo año, en la colonia Lomas de Polanco, los jesuitas llevaron a cabo procesos internos de formación y prácticas de apostolado en escenarios de pobreza acordes con esta mística (Ramírez y Nuncio, 1994), con lo que se convirtieron en los impulsores más significativos de las CEB. Posteriormente, llegaron a la colonia las religiosas de María Reparadora, cuya tarea evangelizadora consistía en la concientización y la educación popular (Gómez, 2011). Desde 1974 se comenzaron a formar 
estas comunidades a partir de los grupos de evangelización y de reflexión con base en los cuales se formulaban propuestas de acción social y participación. La proliferación de estos grupos convirtió a Polanco en el centro del Comité Popular del Sur (Ramírez y Nuncio, 1994).

\section{Los movimientos sociales y las luchas reivindicativas}

La organización de las CEB y su práctica continua de análisis de la realidad fueron la plataforma para participar en las acciones reivindicativas. Dos fueron los factores que intervinieron en la conformación de las primeras redes sociales en las colonias del sur de Guadalajara: la identidad religiosa de los migrantes que conservaban como rasgo de su origen (De la Peña y De la Torre, 1990), y la migración del campo a la ciudad, que se asentó en terrenos que carecían incluso de garantías legales, lo que dificultaba la obtención de los servicios públicos básicos (Ramírez, 1996).

Durante la existencia del Comité Popular del Sur, se realizaron diversas acciones organizativas, como la lucha por el alcantarillado, la pavimentación, la energía eléctrica, los servicios básicos, las cuotas de transporte, entre otras, que marcaron el talante de la colonia y el involucramiento de las CEB en lo que interpretaban como la lucha por la justicia (Gómez et al., 2015):

Esta lucha marcó mucho el estilo de las comunidades eclesiales de base. Incluso la interpretábamos que había sido así, dadas las proporciones, como su éxodo, ¿verdad? cuando se dieron cuenta que podían hacer algo como grupo organizado con esta mística en las comunidades, entonces, pues tomaron fuerza y se vio el valor del método, la mística de evangelización. A partir de entonces, pues empezó a crecer todo, empezamos a acompañarlos (jesuita fundador, HV).

\section{SigNIFICANTE: LA EDUCACIÓN EN CAPACIDADES (FUNDAMENTOS TEÓRICOS)}

Si bien el acercamiento a los pobres aquí descrito se circunscribe a un contexto pastoral, una de las tesis de nuestro trabajo es la presencia condicionante de diferenciales pedagógicos que acompañaron las acciones de los diversos actores en la colonia Lomas de Polanco. Por tal motivo, partimos de enfoques teóricos que permiten esa relación entre la opción por los pobres y las mediaciones pedagógicas.

La reflexión sobre la pobreza adquiere sentido desde un horizonte ético basado en la negación de esta carencia, la cual es un impedimento para el desarrollo, la producción y la reproducción de la vida humana (Dussel, 2014), característica reflejada en las primeras acepciones de la Real Academia Española (s.f.), que define pobre como "necesitado que no tiene lo necesario para vivir" y "escaso, insuficiente". Ser pobre es una situación doliente, inhumana, y la afirmación de la vida humana a partir de diversas mediaciones, entre las que se encuentra la educación, es una negación de esta situación de negatividad existencial (Dussel, 2016).

Desde el enfoque del florecimiento humano propuesto por Boltvinik (2005), estos acercamientos se originan de una pregunta: “QQué son realmente capaces de hacer y de ser las personas? ¿Qué oportunidades tienen verdaderamente a su disposición para hacer o ser lo que puedan?" (Nussbaum, 2012, p. 14). ¿Existen 
mediaciones educativas que pueden tener algún tipo de injerencia en lo que los pobres pueden ser y hacer?

\section{El enfoque de capacidades}

La educación en capacidades es la categoría fundamental recuperada en este análisis. Este enfoque aborda la realidad de la pobreza a partir de una base antropológica que la define como una serie de ausencias considerables en su desarrollo, entendidas como carencia de libertades políticas fundamentales y de privación del respeto a los derechos humanos (Sen, 2000). También se es pobre por no contar con la capacidad de percatarse de los derechos que le son negados ni contar con las posibilidades de hacerlos valer (Nussbaum, 2012). En este contexto, una de las concreciones de la opción por los pobres es ser voz de los que no tienen voz, en particular de los pobres y de los que sufren (CELAM, 1979). Si bien la pobreza es la condición del que carece de lo necesario para la vida, para Sen (2000), el pobre es aquel que carece de las capacidades para llevar la vida que cada quien valora.

Partimos del concepto de dignidad de la vida, en el cual se considera connatural a esta el ejercicio de libertades fundamentales para llevar la vida deseada. Este paradigma considera a la persona como un fin en sí misma, más que un medio, y no solo se ocupa de las condiciones de bienestar, sino de las condiciones traducidas en oportunidades reales disponibles para cada ser humano. Estas oportunidades se conciben como un conjunto de libertades sustanciales que las personas pueden llevar, o no, a la práctica. El desarrollo consiste en la adquisición de estas capacidades (Nussbaum, 2012).

En la propuesta de Nussbaum, la dignidad humana, más que una prerrogativa ontológica del ser humano desde una consideración abstracta, es un conjunto de condiciones que favorecen una vida digna, la cual requiere

la protección de ámbitos de libertad tan cruciales que su supresión hace que la vida no sea humanamente digna (Nussbaum, 2012, p. 52).

El enfoque de las capacidades y de los derechos humanos coincide en torno a la idea de que todas las personas tienen derecho a ciertos bienes centrales en virtud de su humanidad misma, y que uno de los deberes fundamentales de la sociedad es el de respetar y apoyar tales derechos (Nussbaum, 2012, pp. 83-84).

Desde este enfoque, es fundamental expandir la libertad, la cual es, al mismo tiempo, un fin y un medio. Así, la libertad tiene un papel primordial como fin y un papel instrumental como medio del desarrollo. La instrumentalidad de las libertades consiste en que cada una ellas se relaciona una con otra y, a la vez, contribuye a la libertad humana en general (Sen, 2000).

En este sentido, la educación estaría dentro de las oportunidades sociales; asimismo, se encuentra vinculada a la capacidad de reclamar las libertades políticas y hacer uso de estas, la oportunidad de realizar servicios económicos más complejos, una mayor capacidad de discernimiento de la información, y facilidad para ser acreedores de mejores condiciones de seguridad. La educación sería una mediación para la apropiación de las libertades fundamentales que favorecen una vida dignamente humana (Cejudo, 2006). 
Las libertades como posibilidad de lograr la vida deseada se vuelven a su vez capacidades. Estas son condiciones y procesos necesarios para alcanzar la vida buscada (Sen, 2000). Las capacidades no se reducen a habilidades; abarcan tanto facultades humanas, adquiridas o heredadas, como condiciones, por ejemplo, oportunidades y procesos que posibilitan las capacidades. La capacidad de agencia involucra la habilidad de la persona para actuar proactivamente; sin embargo, no se ejerce si se carece de oportunidades y procesos, como la libertad de expresión, condiciones institucionales para el respeto a los derechos humanos, la posibilidad de elaborar demandas sin tener el miedo a perder la vida, entre otros.

Estas capacidades, resultado de condiciones externas y facultades humanas, Nussbaum (2012) las llama capacidades combinadas. Se tiene la capacidad de la educabilidad y, al mismo tiempo, se educa para ampliar el bagaje de capacidades. Las capacidades internas son rasgos, aptitudes y habilidades generadas mediante procesos de entrenamiento y desarrolladas en interacción con el entorno familiar, social, económico y político (Nussbaum, 2012). Estas se distinguen de las capacidades combinadas: al ser las capacidades un asunto de justicia social, una sociedad puede estar invirtiendo en la generación de capacidades internas, pero puede obstruir, mediante la ausencia de oportunidades reales, el desarrollo de capacidades combinadas:

Las capacidades combinadas se definen como la suma de las capacidades internas y las condiciones sociales/políticas/económicas en las que puede elegirse realmente el funcionamiento de aquellas, no es posible conceptualmente imaginar una sociedad que produzca capacidades combinadas sin que antes produzca capacidades internas (Nussbaum, 2012, p. 42).

La educación enfocada a la superación de la pobreza, entendida como ausencia de capacidades, no puede reducirse a un recurso encaminado al aumento de la renta, propio de las visiones provenientes del paradigma del capital humano. Al menos, desde enfoques que parten de la pobreza humana con una visión integral de la persona, la educación es una mediación para conseguir la vida que se pretende vivir (Cejudo, 2006).

Las capacidades no funcionan de manera aislada, sino que interactúan unas con otras:

... tiene mucho sentido que identifiquemos funcionamientos (o, mejor dicho, capacidades) fértiles: oportunidades que generan a su vez otras oportunidades. Las capacidades fértiles serán específicas de sus respectivos contextos hasta cierto punto, pero no es menos cierto que podemos apostar con bastante seguridad a que la educación es una de ellas en todas las naciones, ya que proporciona acceso no sólo a las opciones de empleo y a la voz política, sino también a un mayor poder de negociación en el hogar familiar y, por consiguiente, al poder de valerse por uno mismo de cada persona (Nussbaum, 2012, p. 121).

\section{La formación de capacidades y la educación liberadora}

La relación entre la educación y las capacidades consiste en las condiciones de tiempo y espacio fundamentales para asistir a los espacios educativos, el proceso (domesticador o liberador) (Freire, 1997), las condiciones biopsíquicas de la persona que le permiten el aprendizaje, y las habilidades y experiencias de la vida de la 
persona que condicionan su manera de estar en el acto educativo (Primero, 1999), además de la presencia de educadores como mediaciones (Dussel, 1998).

La capacidad organizativa, de agenciamiento, asociación, compromiso ético, solidaridad, reflexividad y análisis crítico de la realidad son algunas de las capacidades fértiles que se forman en una dinámica de apropiación mediada en un proceso pastoral en interacción crítica con la realidad (Nussbam, 2012). Esta visión delimita la educación propicia para favorecer el desarrollo de estas capacidades, razón por la cual Nussbaum orienta su propuesta hacia una educación enfocada a la reflexión personal, la interpretación de sí, al papel que en ella juega el diálogo, caracterizada como pluralista, su apuesta a valores fundamentales y el respeto a diversos estilos de vida (Primero, 1999).

Esta educación no solo es racional; se involucran las emociones, como el abono que permite que los ideales sociales germinen, den fruto y se sostengan con el tiempo. Las iniciativas orientadas a la praxis de la justicia deben procurar dos misiones fundamentales: el cultivo de emociones que favorezcan vínculos que posibiliten el sostenimiento en compromisos de índole colectiva, sobre todo en proyectos valiosos que requieran paciencia, esfuerzos y sacrificios significativos, y el control del posible surgimiento de emociones que obstaculizan la cohesión social (Nussbaum, 2014).

Estos elementos interactúan para la formación de la personalidad o el talante de los sujetos de acuerdo con las demandas sociales de su entorno en los diversos niveles societales, sea en la familia, comunidad, escuela o sociedad en general (Primero, 2002). Resultado de esta interacción es la conformación de la personalidad, que configura en ella un carácter, un talante, una forma de ser, es decir, un ethos:

Conformación de personalidades y una actividad que involucra a diversas personas que interactúan en algún espacio común, que puede ser emotivo (inmediato al individuo, la familia por ejemplo); interpersonal (mediado necesariamente, la escuela a modo de ilustrar); o social (circunstancial e impersonal, a pesar de que en su origen o entorno haya por necesidad individuos) (Primero, 1999, p. 24).

El fin de esta vertiente pedagógica es la formación de personas para la transformación histórica. Se constituye con instrumentos materiales, simbólicos y relacionales al servicio de la vida humana, Así, la educación se vuelve sinónimo de apropiación, es decir, introyección de la objetividad en la subjetividad a partir de la interacción entre el sujeto y la realidad. Una de las formas de introyección de la exterioridad en la interioridad es desde la deconstrucción de un ethos vigente dominante para construir uno que opere orientado más al beneficio de la comunidad y la vida que al beneficio individual y de la satisfacción inmediata, al procurar mejores condiciones de convivencia ética (Primero, 2002).

Este distanciamiento, reflexivo y crítico a la vez, respecto a la sociedad vigente y la búsqueda de su transformación permite la incorporación de una pedagogía crítica (Ramírez y Quintal, 2011), la cual, como menciona Freire (1996), procura superar la neutralidad política de lo educativo y se ocupa de las condiciones estructurales generadoras de asimetrías sociales, en las cuales a la educación se le presenta la tarea de optar políticamente por velar o develar esos mecanismos generadores de alienación humana, que es también un proceso de indignación y construcción de sujetos críticos (Giroux, 2008). 
La educación no es una práctica separada de la tarea de la transformación social. No es un ejercicio descontextualizado de lo histórico. La educación es reflexión-acción sobre la realidad para transformarla en lo que la realidad misma funge como mediadora del proceso pedagógico y el educador entra en una relación dialógica con los educandos (Freire, 2005).

Esta educación problematizadora, para Freire, responde a la esencia del ser de la conciencia del sujeto, que es la intencionalidad. Esto parte de considerar a la conciencia como escindida, es decir, tiene conciencia de la conciencia, lo que le ayuda a tomar distancia de su entorno para reflexionar de manera crítica sobre él. Como condición para este proceso dialéctico, requiere condiciones: "En un pensar dialéctico, acción y mundo, mundo y acción se encuentran en una íntima relación de solidaridad. Aún más, la acción solo es humana cuando, más que un mero hacer, es un quehacer, vale decir, cuando no se dicotomiza de la reflexión" (Freire, 2005, p. 53).

Esta reflexión en la acción no solo se presenta como un momento previo, sino que se realiza en la praxis política y social en un diálogo con los educandos sobre su acción (Freire, 2019), y si es verdadera reflexión, debe conducir a la práctica.

\section{MÉTODo}

\section{La hermenéutica analógica}

Nuestro estudio se auxilió de la hermenéutica analógica cuya finalidad es la interpretación de textos hiperfrásticos (Beuchot, 2009), es decir, textos que van más allá de la palabra, el enunciado y la frase, lo que demanda un ejercicio de interpretación que se dirige a textos escritos y se abre a realidades como la acción educativa, lo político, la dinámica familiar, entre otras. Beuchot (2011) señala que son susceptibles de ser interpretadas como texto:

... en el aula se toman como texto las conductas del maestro y los alumnos, la interacción didáctica es toda ella un texto conformado por acciones o conductas significativas. Pero también pueden considerarse como textos las obras de arte y otras cosas; incluso sabemos que en diversas épocas se ha tomado al mundo como un texto (p. 27).

La hermenéutica analógica puede tomar a la educación como un texto, en el cual se cruza un caleidoscopio de signos, símbolos e interpretaciones, ya sea que los educadores interpreten a los educandos o viceversa, la manera como se interpretan los contenidos que se transmiten y los que se reciben, de tal modo que ese juego de múltiples interpretaciones que se asocian Gadamer (2005) lo denomina fusión de horizontes. A partir de esa fusión, existen cambios tanto en los educadores como en los educandos.

\section{Técnicas empleadas}

En un primer momento de la investigación, elaboramos un marco sociohistórico a partir de consultas documentales para el conocimiento del contexto de la colonia. Posteriormente, construimos una red de informantes clave con base en los participantes de las CEB de aquella época y sus roles en tales agrupaciones. De tal consulta, obtuvimos a los actores a entrevistar: 
- 12 fundadores, que son actores que iniciaron con las CEB: jesuitas, sacerdotes diocesanos y hermanas reparadoras.

-20 dirigentes: ex jesuitas, jesuitas de ahora que en aquel momento eran novicios, sacerdotes diocesanos, que se suman luego a las comunidades, y dirigentes laicos con influencia importante en la dinámica de las comunidades.

-30 herederos: participantes jóvenes y adultos de aquellos años.

Los fundadores fueron entrevistados utilizando la técnica de historia de vida, y los dirigentes y herederos, con entrevistas en profundidad. Luego, la información se cruzó con cuatro grupos focales. La historia de vida es una técnica inscrita dentro del método llamado historia oral. Con esta, se procura dibujar el perfil cotidiano de la vida de una persona o grupo de personas a lo largo del tiempo. Paralelamente, se destacan y acentúan los rasgos sociales y personales que son significativos en ese discurrir personal del protagonista (Martín, 1995)

En la historia de vida no se considera al sujeto como un informante, sino como un constructor de su mundo en cuanto a cómo se ve a sí mismo en el presente y en relación con su pasado. Asimismo, la historia de vida considera al entrevistado como un sujeto social (Reynaga, 2003). En el caso de Lomas de Polanco, la elección fue sobre historias de vida dimensionadas, ya que no abordamos la biografía del sujeto, sino los aspectos que tienen que ver con el tema de nuestra investigación (Reynaga, 2003).

En la entrevista en profundidad se reconstruye cómo los sujetos cimientan las representaciones sociales de la experiencia relatada a partir de sus individualidades. Mediante esta técnica, se extrae información biográfica del informante, entendiendo esta como el conjunto de las representaciones asociadas a los acontecimientos vividos por el entrevistado, lo que permite una visión diacrónica del objeto de estudio (Alonso, 1995). Esta técnica se implementó en los identificados como dirigentes y herederos.

Las entrevistas en profundidad se complementaron con los grupos de discusión, en los que recuperamos representaciones de carácter colectivo, lo que arrojó conocimiento sobre sistemas de representación colectiva más que de comportamientos (Alonso, 1995). El grupo de discusión es una técnica de investigación social que trabaja con el habla; lo que se dice, se asume como punto crítico, y lo social se reproduce y cambia. En el habla se articula tanto la subjetividad como el orden social (Canales y Peinado, 1995); esto favorece la fusión de horizontes gademeriana. Conformamos cinco grupos de discusión con diversos actores que participaron en este periodo en las comunidades y otros con diversas acciones de voluntariado en la colonia.

Cada una de estas técnicas se implementaron mediante una continua interacción entre la recuperación, interpretación y contraste con los interlocutores mediante la siguiente secuencia temporal: historia de vida, entrevista en profundidad y grupo de discusión. La interpretación de la información se realizó con base en un enfoque hermenéutico y de acuerdo con los significantes, los significados y la significación de los diferenciales pedagógicos identificados en las técnicas. Además, durante las entrevistas hicimos el compromiso de cuidar el anonimato de todos los informantes, razón por la cual omitimos nombres propios en los recortes de las entrevistas empleados en este escrito. 


\section{SIGNIFICADO: LA PRAXIS DE LAS COMUNIDADES ECLESIALES DE BASE Y LA FORMACIÓN DE CAPACIDADES (LOS HALLAZGOS)}

Después de haber delimitado los significantes del estudio en los fundamentos teóricos, presentamos los significados de la praxis educativa desde la opción preferencial por los pobres. Los actores que intervinieron en la colonia Lomas de Polanco se concebían como agentes de la transformación social, junto con los colonos que fueron formando, en la misión de contribuir a la mejora de las condiciones de vida del lugar.

Esta intencionalidad estuvo acompañada de acciones sociales concretas: obras asistenciales, acciones comunitarias organizativas, entre las que encontramos las cooperativas, además de su participación en las luchas reivindicativas, todo con la finalidad de superar las condiciones de precariedad de los habitantes de la colonia, como lo describe el siguiente entrevistado: “... y en torno a esas personas, a esas familias, se promovieron muchas actividades sociales; repito, buscando darles apoyo en su situación tan precaria, tan difícil" (diocesano fundador, HV):

Las principales acciones fueron las cooperativas de producción y de consumo, además de servicios funerarios, orientadas a la satisfacción de necesidades básicas; de estas, la mutual de servicios funerarios sigue funcionando hasta el momento: “... y por otro, digamos un trabajo más en cuestiones de desarrollo y organizativas. Estaba por un lado el trabajo de la cooperativa, había una mutual que era generar un grupo que hacía ahorros juntos y prestaba servicios funerarios a la gente que estaba asociada" (jesuita fundador, HV).

Aunque estas acciones estaban orientadas a la satisfacción de necesidades básicas, en ellas siempre estuvo presente el cariz educativo al pretender sostenerlas desde la autogestión, sin excluir la presencia de la mediación de los jesuitas o de otros actores. Además de estas acciones, la constitución de capacidades para la superación de la pobreza tuvo otras significaciones que exponemos a continuación.

\section{Prácticas de educación no formal y de apoyo a la escolarización}

Diversas fueron las iniciativas de acompañamiento a la escolarización y a la educación no formal que pueden considerarse como capacidades fértiles al ser base para la formación de otras capacidades subsecuentes. Los religiosos y las religiosas llegan a Polanco con una oferta meramente pastoral, pero, atendiendo a la realidad, se comprometen en apoyar en la alfabetización y la educación abierta para adultos: "Formación en lo nuestro, que es el aspecto pastoral, pero claro que como ahí tienen que ver muchos valores, y también cuando ya se ofreció, fue trabajar en la alfabetización" (religiosa fundadora, HV).

Por los lugares de origen de los primeros habitantes de la colonia, al provenir de ambientes rurales, contaban con importantes carencias educativas ante las cuales se implementaron como principales medidas remediales la alfabetización de adultos, que utiliza el método de la palabra generadora de Freire (2005), y el avance en el grado escolar por medio de la educación abierta, con el apoyo de estudiantes avanzados en su nivel de escolaridad.

Las iniciativas educativas en la colonia las emprendieron religiosos y jóvenes voluntarios animados por el compromiso social con el pobre promovido por los 
jesuitas. Estas fueron el Centro Polanco y el Centro de Educación Social Lomas de Polanco (CESLOP). El primero surge de las orientaciones de los jesuitas para atender los sectores de vulnerabilidad y formar, mediante el encuentro, la conciencia social de sus estudiantes. Este centro comenzó auxiliando a las escuelas aledañas con apoyos, desde la psicología educativa hasta las dificultades de aprendizaje, ya que, por las condiciones sociales de los vecinos, les era imposible la asistencia a servicios profesionales: "Y luego de repente, Toño decía: 'pues yo quiero que las mamás participen en esto' y entonces los papás que trabajen con los niños, en lugar de que sea el psicólogo, que sean los papás o la mamá que acompañe al niño a hacer la tarea y entonces darle instrucciones a la mamá" (voluntaria fundadora, HV).

Entre las iniciativas que tenían la pretensión de apoyar la educación formal y la educación de adultos, se encuentra el CESLOP, que se concibe como un proyecto de educación popular con el objetivo de auxiliar procesos en los que el Estado no ha tenido la capacidad de responder a las necesidades educativas en ambientes de marginación urbana:

Pensábamos, por ejemplo, había un gran déficit en las bibliotecas, no había bibliotecas, bueno ¿por qué no hacemos una biblioteca popular? una biblioteca que sea abierta a todo público y que tenga materiales escolares, y otros materiales. Y que nosotros hagamos la función de facilitadores, de promotores de la lectura, no sé, incluso de formadores en el sentido de que hubiera talleres de lectura, seminarios, actividades; que, desde los niños hasta los adolescentes, adultos, pudieran beneficiarse, entrar en una dinámica diferente respecto a la educación (voluntario CESLOP, HV).

De esta manera, no solo favorecieron a la colonia con una infraestructura de apoyo en la educación, sino que, además, realizaron diversas actividades para construir lo educativo como necesidad a partir de la toma de conciencia de los beneficios de esta, al orientarse a la formación de capacidades combinadas (Nussbam, 2012).

\section{La formación en capacidades políticas de los colonos}

Entre los procesos de concientización de los colonos, se encuentra la invitación a la participación política, la cual se interpretaba como un elemento constitutivo del compromiso desde la doctrina social de la Iglesia y la opción preferencial por los pobres: "Que sí buscábamos el bien común, como que ahí había la conciencia política, y que los laicos tenían que asumirla" (jesuita fundador, HV).

La formación política se presentó de diversas maneras: cursos, talleres y pláticas enfocados a la formación política; la participación en las luchas reivindicativas mediante procesos de reflexión acción; y contenidos políticos en sus temáticas pastorales. La relación entre la concientización y la participación en acciones reivindicativas se dio en espiral, ya que desde procesos de concientización se acompañaba a los vecinos de la colonia en las luchas en las que participaron, y de cada una de ellas establecían ejercicios de reflexión.

La dinámica reflexión-acción de la propuesta pedagógica de Freire tuvo como plataforma la participación en las distintas reivindicaciones por parte de los colonos, entre los que se encontraban los miembros de las CEB. La dimensión educativa de estas acciones no solo se deriva del resultado de los análisis de la realidad y la concientización en las comunidades, sino que, además, la participación misma fue una 
ocasión para la reflexión en la capacidad de agenciamiento y empoderamiento que se tenía tras la participación organizada y solidaria de los educandos con el acompañamiento de sus educadores: “... luego participaron en las asambleas nacionales cuatro, y luego también, ahorita no tengo muy claro porque recuerdo que la quinta cosa era también ofrecer servicios en la misma colonia, que primero era más claro porque estaba muy muy difícil la cosa" (jesuita fundador, HV).

Ante la participación en estas acciones organizativas, se dejó de relacionar la prudencia con pasividad con base en la renuncia a ser cómplices de la realidad mediante el silencio, y protestar contra las injusticias con su voz organizada y colectiva. El conflicto no era algo buscado, pero sí asumido como consecuencia:

... y después de eso la gente se quedó ya muy emocionada [ya] que trabajar en equipo y organizados les producía algo bueno, claro que para entonces pues la colonia no tenía ni agua potable, ni luz, ni nada, entonces lo primeritito fue eso [...], porque eran ríos de agua por las calles, y luego ya después de eso empezaron con las cooperativas, que la gente trabajó muy bonita con las cooperativas... (religiosa fundadora, HV).

Las iniciativas que hasta ahora siguen vigentes en Lomas de Polanco son el Centro ITESO-Polanco y la mutua de difuntos, cuya permanencia se debe, a juicio de algunos actores que han pasado por dicho centro, a las necesidades a las que todavía responden: "Pues la gente no deja de morirse y las necesidades educativas continúan vigentes al día de hoy" (grupo focal Lomas de Polanco). Por tal motivo, pretendemos ofrecer un panorama más amplio de lo que permanece hoy en los actores participantes desde la recuperación de su voz; a continuación, presentamos los hallazgos concernientes a los saldos educativos.

\section{LA SIGNIFICACIÓN: LAS CAPACIDADES COMO SALDO (DISCUSIÓN)}

La significación de estas prácticas se refleja en la formación de algunas capacidades como saldo. Desde la recuperación de la subjetividad, el enfoque se orienta hacia la formación de capacidades internas, las cuales fueron también fértiles en la medida en que se convirtieron en un potencial para el desarrollo de otras capacidades y funcionamientos.

La recuperación realizada años después para esta investigación nos permite visualizar diversas posibilidades de puesta en funcionamiento de las capacidades formadas y sus impactos interpretados desde la sutileza de la fusión de horizontes a partir de la narrativa de los entrevistados. Entre los funcionamientos, existen importantes variaciones en campos, tiempos y maneras de concreción, las cuales relatamos a continuación.

\section{La toma de conciencia como capacidad}

La praxis reflexión-acción no solo produjo algunos logros reivindicativos en el marco temporal del estudio, además de transformaciones significativas en el sujeto; como se muestra en los testimonios de los participantes, se gestó un proceso de apropiación de recursos cognitivos, axiológicos y procedimentales para interpretar e intervenir en su realidad. 
Como resultado de los procesos de concientización por parte de los educandos, los entrevistados dejaron de considerar la pobreza o carencia de servicios básicos como una situación natural ante la cual tenían que mantener una actitud pasiva de resignación. Tras la intervención de los educadores y el contagio de ideales, fue posible que se involucraran en acciones reivindicativas como resultado de la conciencia despierta:

... un fruto muy importante ha sido la conciencia social. O sea, yo sí creo que la gente, que la colonia pudo haber recibido la oportunidad de vivir más despierta que dormida digamos, o todavía más claro, más despierta que drogada, como con mucha conciencia social de que hay mundo, de que hay situaciones, de que hay luchas que tiene uno que hacer, que hay hermanos, que hay sufrimiento, que hay esperanza, que hay vida. Eso sería lo que yo tendría como por estar despiertos (jesuita fundador, HV).

Además de que aprendieron una lectura creyente de la realidad, esta no careció de crítica al desmitificar la condición de pobre con una visión que invita al compromiso con la realidad, más que prescripciones dogmáticas o disciplinarias que consideran distantes de su realidad:

... fueron también formados en esa situación reivindicativa, crítica, de resistencia, de hacer propuestas alternativas, de una visión de Iglesia menos encerrada en el templo, menos conservadora, es como la tónica eclesial aquí en Guadalajara, ¿verdad? más de culto (jesuita fundador, HV).

Así, la concientización permanece hoy como capacidad fértil manifestada de diversas formas, según su situación de vida y contexto.

Tabla 1. Manifestaciones de la concientización

\begin{tabular}{|c|c|c|c|}
\hline Análisis de la realidad & Conciencia & Solidaridad & Habilidades organizativas \\
\hline $\begin{array}{l}\text {... vengo con toda } \\
\text { esa formación desde } \\
\text { el momento en que } \\
\text { cambia mi pers- } \\
\text { pectiva de analizar } \\
\text { la realidad, pues la } \\
\text { vida, de este, que } \\
\text { no se trataba nada } \\
\text { más de tener buenas } \\
\text { intenciones (joven } \\
\text { participante, EP) }\end{array}$ & $\begin{array}{l}\text {... me hizo saber } \\
\text { que era más huma- } \\
\text { no, me hizo tomar } \\
\text { más conciencia de } \\
\text { lo que pasaba en } \\
\text { la sociedad en mi } \\
\text { estado, en mi país } \\
\text { (joven participante } \\
\text { EP) }\end{array}$ & $\begin{array}{l}\text {... sí, como les regalo } \\
\text { mi trabajo y les regalo } \\
\text { un día o dos, hay quien } \\
\text { me dice oye ocupamos } \\
\text { unas fotografías, en tal } \\
\text { parte, por tres horas de } \\
\text { trabajo les hice toda la } \\
\text { campaña de Revlon, les } \\
\text { hice todo el catálogo de } \\
\text { temporada y me gane } \\
\text { cuarenta mil pesos, y a la } \\
\text { semana siguiente me fui a } \\
\text { Chapala y les ayude a los } \\
\text { pescadores y me salieron } \\
\text { ampollas en las manos y } \\
\text { no me gane nada (joven } \\
\text { participante, EP) }\end{array}$ & $\begin{array}{l}\text {... todas esas técnicas si las aprendí } \\
\text { de con ellos, [...] como mi trabajo } \\
\text { popular en este sentido de que no } \\
\text { tenía ninguna experiencia yo. Tenía } \\
\text { la idea, tenía una ideología, pero } \\
\text { no tenía esa experiencia de trabajo } \\
\text { popular, ¿de cómo organizarse, } \\
\text { no? Y como si se puede organizar a } \\
\text { gente desde abajo sin una directriz } \\
\text { entre nosotros, en redondo ¿no? } \\
\text { horizontalmente eso sí lo aprendí } \\
\text { de con los jesuitas (Norberto Villa- } \\
\text { señor, EP) }\end{array}$ \\
\hline
\end{tabular}

\section{La capacidad de agencia}

Entre las prácticas de educación, se promovió la generación de actores sociales que fueran protagonistas de su realidad desde lo político, lo eclesial o lo social. Para ello, en las prácticas comunitarias de reflexión dentro de las CEB cada uno de los participantes tenía voz y en las conversaciones se educaba para el agenciamiento por medio de la reflexiones de los mismos participantes.

La formación en la agencia fue desde la participación activa y su reflexión evaluativa. 
Los miembros de las CEB aprendieron a evaluarse, analizarse y a estar en un proceso de mejora continua:

... Ellos eran llamados a organizar [...] ellos eran también ya responsables de la organización que se iba creando de eventos importantes, de procesos importantes, ese tipo de formación era la que se daba; evaluando, pero como cabezas ya, no era una formación como de alumnos, era una evaluación donde haciendo, ellos fueron formándose, ellos fueron formándose haciendo, haciendo (diocesano fundador, HV).

En las comunidades de jóvenes no se escatimó en la edad para constituirlos en agentes de pastoral de la parroquia, y estos maduraron al asumir responsabilidades y al comprometerse. Algunos de los jóvenes participantes eran de corta edad y migrantes del ámbito rural; por medio de estos procesos, aprendieron a vencer la timidez para hablar y decir su palabra:

... eran unas adolescentitas cuando estaban allí en Polanco y ahí se les incursó juntamente con veinte, treinta, cuarenta personas de allí, pero como donde quiera, reunían el ciento por uno, como dice la parábola de San Gregorio, otras el treinta, otras el sesenta, pero ellas son como un fruto bien claro de las maravillas de esa formación (diocesano fundador, HV).

La formación en la agencia comenzó por la propia valoración de sí. La gente que no se apreciaba lo suficiente para defender por sí misma sus derechos y que sentían la necesidad de refugiarse en la presencia y en la voz de sus educadores aprendieron a valorarse, a sentirse capaz de defenderse y defender sus derechos, a hablar en público dentro de la dinámica de las CEB y a alzar su voz para manifestar sus demandas en las acciones reivindicativas: "Pues yo creo que el valorarse ellos. Por ejemplo, las vecinas me decían: 'madre, cuando vayamos a las oficinas de gobierno, hable usted, porque a nosotros no nos toman en cuenta, no nos hacen caso'" (religiosa fundadora, HV).

Gracias a la autovaloración lograda por medio de la reflexión dentro de las comunidades, lo que consideraban inalcanzable lo comienzan a ver como posible, no como una esperanza cumplida, sino como resultado de la construcción de su realidad por medio de la organización y la participación:

... si había mucha motivación, mucha promoción, no eran soluciones espontáneas -que algunas sí porque se necesitaban urgentemente- pero también había la promoción de enseñarles cómo educarse ahí levantándose, ahí promoviéndose ellos, eso ya como en un caminito, en un proceso de los que quisieron y se dedicaron a ayudar, pues perseveraron y experimentaron que la vida podía cambiar, pero les llevó un esfuerzo, un esfuerzo de perseverar de un estilo de ser (diocesano fundador, HV).

La toma de conciencia se describe como un aprendizaje tanto para habitantes como educadores; aprendieron que los pobres pueden ser capaces de luchar por sí mismos para salir de su situación, y que son educables. Aprenden la necesidad de procesos de educación en su promoción y la ineficiencia de los programas asistenciales como capaces ellos mismos de mejorar su situación. Los pobres, a nivel cristiano, dejan de ser los receptores de las obras de caridad y, en el orden gubernamental, los excluidos del progreso y destinatarios del auxilio del Estado protector. Mediante procesos educativos, pueden luchar para mejorar sus condiciones de vida:

... yo pienso que esa experiencia de las comunidades eclesiales de base hizo que despertáramos todos y también nos hizo conscientes de que no es fácil saber crear cariños verdaderos, no es toma veinte pesos, toma estas tejas, hay que buscar caminos en donde verdaderamente a la persona se le ayude a buscarse, a encontrarse profundamente 
consigo misma, para que se dé cuenta de lo que él puede y debe de hacer (diocesano fundador, HV).

Los logros que los colonos se adjudicaron como propios contribuyeron a su formación como actores sociales, de ahí que tengan una dimensión pedagógica, al suscitarse una dinámica de reflexión en la acción: con cada reivindicación, ellos se fueron considerando capaces del logro de metas organizativas y de lucha por sus derechos desde la horizontalidad de las relaciones humanas y la participación en las acciones educativas.

La capacidad de agencia resulta fértil para el involucramiento en acciones organizativas análogas mediante la disponibilidad para participar en nuevos grupos, sean religiosos de la parroquia o de cualquier otra índole: “... lo que me ayudó fue a ser una persona, lo vuelvo a mencionar, sociable, abierta, más íntegra, seguro, si alguna vez se apareciera la oportunidad de que alguien me pudiese invitar a algún grupo activo, órale, me gustaría" (joven heredero, EP).

Esta disponibilidad se concreta en la participación en diversas acciones organizativas al momento en el que realizamos las entrevistas para nuestro estudio (ver tabla 2).

Tabla 2. Acciones participativas en la actualidad

\begin{tabular}{|c|c|c|c|}
\hline Filantropía & Movimientos sociales & Educación infantil & Acciones culturales \\
\hline $\begin{array}{c}\text {... creo que una vez } \\
\text { estuvieron ahí con los } \\
\text { de Norberto, creo que } \\
\text { están ahí los del sida, } \\
\text { gente que trabaja con } \\
\text { el sida (joven heredero, } \\
\text { EP) }\end{array}$ & $\begin{array}{l}\text { Felipe Castorena, que está } \\
\text { hasta la fecha en Estados } \\
\text { Unidos, anda bien metido } \\
\text { con el movimiento de los } \\
\text { latinos allá. Fíjate que, de } \\
\text { alguna forma, lo veo y veo } \\
\text { que todos tenemos algo } \\
\text { más que hacer, de hecho } \\
\text { déjame enseñarte esto } \\
\text { [...] me regalaron este } \\
\text { reconocimiento el domin- } \\
\text { go porque de hecho les } \\
\text { apoyo cada mes para un } \\
\text { movimiento que tienen en } \\
\text { Polanco (joven heredera, } \\
\text { EP) }\end{array}$ & $\begin{array}{c}\text { Hasta la fecha cada año } \\
\text { sigo haciendo la posada a } \\
\text { los niños con dinero de mi } \\
\text { bolsa y organizo la posada } \\
\text { como para } 500 \text { chiquillos } \\
\text { que no sé de dónde salen } \\
\text { tanto chingado escuincle, } \\
\text { la esquina es mía, compre } \\
\text { la casa del otro lado, y en } \\
\text { la esquina tenía un taller } \\
\text { de lectura (joven herede- } \\
\text { ro, EP) }\end{array}$ & $\begin{array}{l}\text {... también los caminos de } \\
\text { la cultura, por ejemplo; en } \\
\text { mi caso me metí más a los } \\
\text { caminos de la cultura de } \\
\text { barrio; los caminos de los } \\
\text { medios de comunicación } \\
\text { alternos de barrio son po- } \\
\text { sibles y tienen éxito, basta } \\
\text { nada más, este hacerlo con } \\
\text { calidad y ser perseveran- } \\
\text { tes; en eso estoy conven- } \\
\text { cidísimo (joven heredero, } \\
\text { EP) }\end{array}$ \\
\hline
\end{tabular}

\section{La educación como capacidad fértil}

Una de las mayores evidencias de la presencia de diferenciales pedagógicos es el valor otorgado a la educación a partir de la identificación del aporte formativo de las prácticas pastorales en las que participaron. Lo educativo se considera una puerta que abre a mejores opciones de vida como resultado de lo que quedó en ellos de los procesos de las CEB:

Yo creo que aprendieron cómo la gente puede luchar, salir adelante, superarse, etcétera [...] y como no se necesita, ¿qué te diré,? a veces invertirle, no que invertir a la educación, sino, no necesariamente tienes que, ¿cómo te lo explico?, igastar mucho dinero para la formación!, ¿sí? o sea, yo pienso que parte de eso se llevaron, y bueno dentro de su proceso de formación, pues yo creo que aprendizaje (joven heredera, EP). 
Las acciones pastorales contribuyeron a la educabilidad de los habitantes de la colonia, especialmente los jóvenes, lo que generó un impacto directo en la formación de su personalidad:

... yo creo que parte de lo que aprendí, o sea, yo sí, yo, por ejemplo, me dicen que yo leo mucho, ¿en qué sentido?, en todos los sentidos, yo siento que viví ¿cómo te diré? Como con una plenitud esa etapa, o sea, yo no pasé muchas etapas, de mucho estrés, de mucha rebeldía, y todo, yo siento porque esto, estaba ocupada, eso me generaba, me generó una formación (joven heredera, EP).

Del valor que le otorgaron a la educación deriva la continuidad en su proceso formativo tiempo después de su participación en las CEB: “... ya después hice también mi diplomado en derechos laborales, terminamos el diplomado de teología después de dos o tres años, después de muchos porque era cada viernes dos horas, y duramos por lo menos dos años y medio (joven heredera, EP).

Entre los habitantes de la colonia, pese a lo desfavorable de sus condiciones, hubo personas que lograron avanzar en sus niveles de escolaridad, incluso algunas terminaron sus estudios en una carrera profesional. Si bien en Polanco no se desarrollaron proyectos de educación formal, sí existieron iniciativas de apoyo a esta, mediante la cual la educación se reivindicaba como un derecho, independientemente de las condiciones de precariedad económica de los sujetos.

Como iniciativas de la educación popular, por parte del CESLOP, tuvieron una orientación hacia la educación de adultos, de ahí que presentaron algunos saldos tanto en la alfabetización como en los avances en la escolarización en miembros de la colonia: “... eran adolescentes y adultos. Tuvimos varios alumnos que se graduaron de la primaria y de la secundaria, aprovechamos esto de la educación abierta, que en aquel momento estaba planteándose como una alternativa" (voluntario CESLOP, HV).

Aun cuando el CESLOP no era una propuesta de educación formal, sí se concibió como un apoyo alternativo para las escuelas de la colonia que, junto con el Centro Polanco, colaboró para combatir el rezago, el abandono de los estudios y el bajo rendimiento de los estudiantes, además de que se formularon propuestas alternativas de educación integral de las que carecía la educación pública. No solo se contrarrestaron los factores de riesgo del abandono y retraso en los estudios de primaria y de secundaria, sino que fue posible sembrar en los niños y las niñas el ideal del avance en sus estudios y aspirar algunos a una carrera profesional. En los niños y adolescentes de la colonia, el avanzar en sus estudios comenzó a aparecer en sus aspiraciones al considerar estos ideales como posibles:

Por ejemplo, también niños que nos siguieron fielmente durante mucho tiempo, y creo que logramos fomentar este interés por la educación, digamos escolarizada, por el saber, por el estar inquietos, y bueno [...] Niños que yo no sé qué hubiera pasado en otra circunstancia, pero que de algún modo los veíamos pasar de la primaria, a la secundaria y luego que tenían el proyecto de estudiar una carrera, de una familia que difícilmente se podría pensar que ellos sostendrían una carrera (voluntario CESLOP, HV).

Así, la oferta de una vida distinta al fatalismo de las condiciones de pobreza de la colonia provocó que los jóvenes aprendieran a tener metas, un proyecto de vida, ver más allá de sus circunstancias y tener ideales: "Se dieron pasos a nivel individual, como los que hemos dicho de los jóvenes que siguieron distintas carreras o 
según sus perfiles, el de Alfredo artista, el otro [en] Petróleos Mexicanos, pos varios ¿verdad? que podemos ir haciendo lista de gente que logró salir con sus carreras" (jesuita fundador, HV).

Por medio del Centro Polanco, con la influencia de la tendencia de los jesuitas a la inserción en los lugares de marginación, movidos por el ideal de la opción preferencial por los pobres, y con la búsqueda de la coherencia con este ideal y los institutos educativos de financiamiento privado de los jesuitas, se optó por iniciar proyectos de inserción de estudiantes de estas instituciones para implementar este ideal mediante la formación de la conciencia de los estudiantes universitarios.

En las entrevistas a los fundadores pudimos advertir algunos saldos tanto en la formación de la conciencia social de los estudiantes como en su formación profesional, al contar con un espacio que les permitió la puesta en práctica de los conocimientos adquiridos en las aulas universitarias.

El Centro Polanco resultó una novedad frente a las acciones de voluntariado tradicionales en instituciones filantrópicas, puesto que en él se generó un itinerario de inserción entre la gente de la comunidad, más que la ayuda ocasional en situaciones críticas:

... mira yo valoro mucho que una cuestión muy emprendedora, muy de avanzada, una, experiencia muy nueva para la universidad, para los estudiantes. Que fue algo muy innovador, realmente. Que en Guadalajara no había experiencias de esa naturaleza y que creo que abrió la cancha para otros proyectos similares de otras universidades y del mismo ITESO (voluntaria Centro Polanco, HV).

Tabla 3. Saldos educativos

\begin{tabular}{|c|c|c|c|}
\hline Alfabetización & Desarrollo humano & Escolarización & Formación permanente \\
\hline $\begin{array}{l}\text { Y pues en muy poquito } \\
\text { tiempo aprendí a leer; me } \\
\text { regaló un libro que tenía } \\
\text { letra de molde y de la ma- } \\
\text { nuscrita (adulto, EP) }\end{array}$ & $\begin{array}{l}\text {... una de las cosas que } \\
\text { te deja a nivel personal } \\
\text { es que tú descubres que } \\
\text { puedes hacer muchas } \\
\text { cosas y aprender muchas } \\
\text { cosas para ti como persona } \\
\text { también, ¿no? o sea, des- } \\
\text { cubres tus potencialidades } \\
\text { (joven, EP) }\end{array}$ & $\begin{array}{l}\text { Entonces hubo un número } \\
\text { muy alto de gente que es- } \\
\text { tudió carrera (joven, EP) }\end{array}$ & $\begin{array}{c}\text {... ya después hice también } \\
\text { mi diplomado en derechos } \\
\text { laborales. Terminamos } \\
\text { el diplomado de teología } \\
\text { después de dos o tres } \\
\text { años, después de muchos } \\
\text { porque era cada viernes } \\
\text { dos horas, la verdad era } \\
\text { vernos y duramos por lo } \\
\text { menos dos años y medio } \\
\text { (joven, EP) }\end{array}$ \\
\hline
\end{tabular}

\section{Capacidad para defender sus derechos}

La participación en las luchas reivindicativas acompañadas de la dinámica reflexiónacción dentro de las CEB tuvo un potencial educativo que derivó en el desarrollo de la capacidad de los habitantes de la colonia para defender sus derechos: “... leyes, hay que saber por qué no te cobran [...] estas cosas, tú vas haciendo un aprendizaje, aprendizaje, aprendizaje y tú dices: es que yo tengo unos derechos y puedo exigir, ¿sí? Y te vuelves una persona yo creo que ¡positiva! Y ¿cómo se dice? yo pienso que constructiva, ¿no?" (joven heredera, EP).

Algunos participan en la actualidad en la defensa de derechos humanos desde diversos ámbitos y algunos todavía trabajan con jesuitas: 
Es el Centro de Reflexiones CEREAL [que] tiene oficinas en la Ciudad de México y aquí en Guadalajara y su ángulo de trabajo son los derechos laborales, entonces aquí damos cursos, diplomados a trabajadores, sobre todo de derechos laborales, producimos material educativo sobre distintos derechos e investigamos condiciones laborales y publicamos reportes de eso; damos asesoría legal, dialogamos con las empresas para tratar de mejor las condiciones laborales y, además, ahora que el mundo está globalizado, pues somos parte de redes nacional, internacionales, para empujar cambios sobre todo en la industria de aquí, que es la más grande en Jalisco, es la industria electrónica en ese sector sobre todo para impulsar esos cambios (joven heredero, EP).

Como resultado de los procesos de concientización y participación organizada, los colonos lograron las reivindicaciones que se propusieron en sus luchas, lo cual difícilmente hubiera sido posible sin la intervención educativa de los actores. Esto trajo importantes saldos educativos derivados de los procesos de reflexión en la acción. En las prácticas de apoyo a la educación formal también se educó a los padres de familia para la organización de reivindicaciones en el interior de los planteles educativos. Gracias a estos procesos de involucramiento, los padres de familia aprendieron a organizarse dentro de las escuelas para reivindicar derechos, hacer demandas concretas y, así, participar en la búsqueda de mejores condiciones educativas en la colonia.

Estos logros internos de las escuelas están asociados a la reivindicación del derecho a la educación:

... yo creo que hubo muchas situaciones en donde yo sentía que de algo servía lo que hacíamos, por ejemplo, con esto que les digo de los padres de familia, de las sociedades de padres de familia, hubo escuelas en donde se logró que se bajara una cuota, que se respetaran los padres que no habían dado la cuota, que no era obligada, y fueron resultados concretos (voluntario CESLOP, HV).

\section{Conclusión}

Cada una de las capacidades mencionadas en este artículo resultó fértil para mejorar algún aspecto de la realidad inmediata y local de los participantes; además, trascendió en la formación de un ethos solidario, consciente y recíproco en muchos de los participantes. A pesar de estos beneficios educativos recuperados, en muchos continúa abierta la herida de la partida de los jesuitas de la colonia, lo cual debilitó la capacidad institucional para mantenerse organizados y perseverar con el dinamismo de concientización que mantuvieron en el periodo narrado.

Las capacidades se anidan en la subjetividad como una semilla que emerge en distintos espacios personales y comunitarios en los que ha transitado la vida de los participantes. Si bien la experiencia de Lomas de Polanco se debe a determinaciones espacio-temporales muy concretas que imposibilitan el trasplante acrítico en otros contextos, existen situaciones que pueden ser iluminadas con las hipótesis abductivas de esta investigación. Los movimientos urbanos del pasado eran los Quijotes que luchaban contra los molinos de viento de los aparatos políticos rígidos concebidos desde el Estado benefactor, y ahora se lucha contra la exclusión que de lo público ocasionan las continuas privatizaciones. 
La mercantilización de la vida origina nuevas metáforas que evocan una promesa de felicidad desde la posibilidad de formar parte de la sociedad de consumo. En las CEB se descubren otras dinámicas posibles generadoras de sentido y de prendamiento de la propia vida.

La fusión de horizontes realizada en esta investigación, en la cual el pasado se interpreta desde la historia (Gadamer, 2005), por la distancia del tiempo en el que suceden los acontecimientos narrados (1976-1994) y la recolección de la información mediante el estudio de campo, es posible recuperar el impacto en la actualidad de tales experiencias educativas, más allá de sus consecuencias inmediatas.

\section{REFERENCIAS BIBLIOGRÁFICAS}

Alonso, L. E. (1995). Sujeto y discurso: el lugar de la entrevista abierta en las prácticas de la sociología cualitativa. En J. Delgado y J. Gutierrez. Métodos y técnicas cualitativas de investigación en ciencias sociales (pp. 225-240). España: Síntesis.

Beuchot Puente, M. (2015). Teoría semiótica. México: Universidad Nacional Autónoma de México.

Beuchot Puente, M. (2011). Manual de filosofía. México: Ediciones Paulinas.

Beuchot, M. (2009). Tratado de hermenéutica analógica. Hacia un nuevo modelo de interpretación (3a. ed.). México: Ítaca.

Boff, L. (1992). Iglesia: carisma y poder. Ensayos de eclesiología militante. Santander, España: Sal Terrae.

Boff, C. (1990). Epistemología y método de la teología de la liberación. En I. Ellacuria y J. Sobrino. Conceptos fundamentales de teología de la liberación (pp. 79-114). Madrid: Trotta.

Boltvinik, J. (2005). Ampliar la mirada. Un nuevo enfoque de la pobreza y el florecimiento humano. Papeles de Población, núm. 44, vol. 11.

Canales, M. y Peinado, A. (1995). Grupos de discusión. En J. Delgado y J. Gutiérrez. Métodos y técnicas cualitativas de investigación en ciencias sociales (pp. 287-316). España: Síntesis.

Cejudo Córdoba, R. (2006). Desarrollo humano y capacidades. Aplicaciones de la teoría de las capacidades de Amartya Sen a la educación. Revista Española de Pedagogía, núm. 234, pp. 365-380.

CELAM (1979). Documento de Puebla. III Conferencia General del Episcolado Latinoamericano. Puebla. Recuperado de http://www.cpalsj.org/wp-content/ uploads/2013/03/Puebla-III-CELAM-ESP.pdf

CELAM (1968). II Conferencia del Episcopado Latinoamericano. Medellín, Colombia.

De la Peña, G. y De la Torre, R. (1990). Religión y política en los barrios populares de Guadalajara. Estudios Sociológicos, vol. VII, núm. 24, pp. 571-602.

Dussel, E. (2016). 14 tesis de ética. Hacia la esencia del pensamiento crítico. México: Trotta.

Dussel, E. (2014). 16 tesis de economía política: interpretación filosófica. México: Siglo XXI.

Dussel, E. (1998). Ética de la liberación en la edad de la globalización y de la exclusión. Madrid: Trotta. 
Dussel, E. (1979). Dinámica de la opción de la Iglesia de los pobres (1968-1979). Bogotá: CEHILA-CODECAL.

Floristán, C. (1998). Teología práctica. Teoría y praxis de la acción pastoral. Salamanca: Sígueme.

Freire, P. (2005). Pedagogía del oprimido (55 edición). México: Siglo XXI Editores.

Freire, P. (1997). La educación como práctica de la libertad (45 edición). México: Siglo XXI Editores.

Freire, P. (1996). Política y educación. México: Siglo XXI editores.

Gadamer, H.-G. (2005). Verdad y método. Salamanca: Sígueme.

Giroux, H. (2008). Teoría y resistencia en educación. México: Siglo XXI Editores.

Gómez Gómez, E. N. (2011). Habitar el lugar imaginado: formas de construir la ciudad desde un proyecto educativo político. Guadalajara: ITESO.

Gómez Gómez, E. N., Penilla, O., Vaca, A. y Pérez, B. (2015). Lomas de Polanco. Del desencanto al encantamiento del espacio. En E. N. Gómez Gómez. Agentes y lazos sociales: la experiencia de volverse comunidad (pp. 51-81). Guadalajara: ITESO.

Lois, J. (1991). Opción por los pobres. Síntesis doctrinal. En J. M. Vigil. La opción por los pobres (pp. 9-18). Santander: Salterrae.

Martín García, A. V. (1995). Fundamentación teórica y uso de las historias y relatos de vida como técnicas de investigación en pedagogía social. Aula, núm. 7, pp. 41-60.

Morfín Otero, G. (1979). Análisis de la legislación urbana, su aplicación y consecuencia. El caso Lomas de Polanco. Universidad de Guadalajara.

Novaes, R. (1995). Raíces y alas. Cambios y constantes en las comunidades de base. Nueva Sociedad, num. 136, marzo-abril, pp. 70-81.

Nussbaum, M. (2014). Las emociones políticas: ¿Por qué el amor es importante para la justicia? México: Paidós.

Nussbam, M. (2012). Crear capacidades. Propuesta para el desarrollo humano. Barcelona: Paidós.

Primero Rivas, L. E. (1999). Emergencia de la pedagogía de lo cotidiano. México: Primero Editores.

Primero Rivas, L. E. (2002). Epistemología y metodología de la pedagogía de lo cotidiano. México: Primero Editores.

Ramírez Romero, J. L. y Quintal García, N. A. (2011). ¿Puede ser considerada la pedagogía crítica como una teoría general de la educación? Revista Iberoamericana de Educación Superior vol. 2, núm. 5, pp.114-125.

Ramírez Sains, J. y Nuncio Hermosillo, H. (1994). Entre la Iglesia y la izquierda: el Comité Popular del Sur. Guadalajara, Jalisco: Universidad de Guadalajara.

Ramírez Sainz, J. M. (1996). La internacionalizaicón y las identidades del movimiento urbano popular en el área metropolitana de Guadalajara. Espiral, pp. 177-195.

Real Academia Española (s.f.). Diccionario de la Lengua Española. Recuperado de http://dle.rae.es/?id=E05CDdh

Reynaga Obregón, S. (2003). Perspectivas cualitativas de investigación en el ámbito educativo. La etnografía y la historia de vida. En R. Mejía Arauz y S. A. 
Sandoval. Tras las vetas de la investigación cualitativa (pp. 123-154). Guadalajara: ITESO/Conacyt.

Richard, P. (2008). Iglesia del futuro, futuro de la Iglesia. Voces-Diálogo Misionero Contempoáneo, núm. 31, vol. 16, pp.151-154.

Richard, P. (1984). La Iglesia de los pobres en el movimiento popular. CONCILIUM. Revista Internacional de Teología, núm. 196, pp. 331-340.

Sen, A. (2000). Desarrollo y libertad. Argentina: Planeta.

Vázquez, M. A. (1997). Structural obstacles to grassroots pastoral practice: The case of a base community in urban Brazil. Sociology of Religion, vol. 58, núm. 1, pp. 53-68. doi:https://doi.org/10.2307/3712106 